\title{
Changes within the "normal" cerebral white matter of multiple sclerosis patients during acute attacks and during high-dose cortisone therapy assessed by means of quantitative MRI
}

\author{
M BRAININ,* A NEUHOLD $\ddagger$ T REISNER, $\uparrow \S$ E MAIDA, $\dagger$ S LANG, ${ }^{*}$ L DEECKE $\dagger$ \\ From the Neurologische Abteilung, ${ }^{*}$ NÖ Landeskrankenhaus Klosterneuburg, Neurological University Clinic \\ Vienna, $\dagger$ and Institut $f$ Bildgebende Diagnostik, Krankenanstalt Rudolfinerhaus, $\ddagger$ Austria
}

SUMMARY Changes in the apparently unaffected cerebral white matter of multiple sclerosis (MS) patients were studied during acute attacks as well as during high-dose prednisolone therapy. Serial MR scans of patients with a clinically definite diagnosis were performed on four defined occasions: before an episode, within three days after its onset, after 10 days of therapy as well as four weeks later. Thirteen patients agreed to cooperate in forming a MRI data base and to be rescanned immediately after the onset of an acute relapse. Within one year, six patients had such episodes, one of them had a second bout. Both T1 and T2 relaxation times within the apparently normal white matter were significantly prolonged in all cerebral lobes compared to a control group of healthy volunteers. During the acute attacks as well as during therapy the $\mathrm{T} 1$ values remained as before. The $\mathrm{T} 2$ values were elevated only in two out of six cases during the episode. After therapy a considerable clinical improvement was seen in all cases, but a significant T2 decrease as a possible effect of cortisone was noted in only one case. We conclude that the prolonged relaxation times $\mathrm{T} 1$ and $\mathrm{T} 2$ within the apparently normal cerebral white matter of MS patients are the result of a number of molecular events differing considerably among individual patients and that serial measurements of these relaxation times do not consistently change during an acute relapse and do not reflect clinical improvement after high dose prednisolone therapy.

According to a number of studies ${ }^{1-3}$ the measurement of the relaxation times $\mathrm{T} 1$ and $\mathrm{T} 2$ within the visually normal cerebral white matter in cases of multiple sclerosis (MS) has offered some interesting possibilities for the clinical use of quantitative magnetic resonance imaging (MRI). It was shown that the apparently normal cerebral white matter has longer $\mathrm{T} 1$ and $\mathrm{T} 2$ relaxation times than normal controls. These findings demonstrate in vivo what has been concluded from earlier neuropathological reports ${ }^{4}$ that MS is not a disease restricted to focal areas of demyelination but rather involving the entire cerebral white matter.

The clinical significance and the biophysical nature

Correspondence to: Dr Michael Brainin, Department of Neurology, NÖ Landeskrankenhaus Klosterneuburg, Hauptstrasse 2, A-3400 Klosterneuburg, Austria.

§Deceased December 1988.

Received 11 November 1988 and in revised form 24 May 1989. Accepted 5 July 1989 of this finding have mostly remained unclear to date. In another study ${ }^{5}$ the normal cerebral white matter of two groups of MS patients, differing only in the duration of their disease, were investigated by means of quantitative MRI. Only patients with a longstanding course of the disease ( $>5$ years) showed a T2 prolongation in the apparently normal periventricular white matter compared with the group with a shorter disease duration ( $<5$ years) or with another group of healthy controls. The conclusion from this finding was that the prolongation of $\mathrm{T} 2$ develops gradually and is more pronounced in the later stages. Although the specificity of $\mathrm{T} 1$ and $\mathrm{T} 2$ measurements within the apparently normal cerebral white matter has not yet been established, there is reasonable hope for quantitative MRI to be used as a sensitive paraclinical method for documenting the progression of the disease. In another study ${ }^{6}$ quantitative MRI has shown some potential for assessing treatment and in helping to understand the mechanism of action of therapeutic agents in multiple sclerosis patients. 
The purpose of this study was to ascertain whether such changes in relaxation times of the apparently normal cerebral white matter occur during an acute relapse and whether these measurements are subject to changes during high-dose cortisone therapy.

\section{Patients and methods}

Thirteen patients with a clinically definite diagnosis of MS (Poser Criteria) and a recent inception of the illness (mean: 2.7 years, range: $0.5-3.5$ years) as well as with mild physical impairment (Expanded Disability Status Scale (Kurtzke): Grade 0-2) agreed to cooperate in forming a data base and to be rescanned immediately after the onset of a bout. All patients had a remitting and relapsing course of the disease and had shown at least one bout with a cerebral localisation. In all patients the cerebrospinal fluid examination had revealed oligoclonal bands as well as elevated intrathecal IgG production. In addition, the disseminated character of the disease was demonstrated by means of conventional MRI showing high-signal lesions on the spinecho sequences that were regarded as characteristic. In no case were the MRscans normal. No patient had had a bout in the preceding three months and only patients without long-time medication (cortisone and azathioprin) were accepted. All patients were regularly seen in the MS outpatient service of the Vienna Neurological University Clinic. All episodes were diagnosed by unequivocal clinical signs. Within one year six patients had had episodes, one of them a second bout. The clinical and MRI data of these patients are summarised in table 1.

The first examination was performed when the patient entered the study. Another scan was made within three days after the onset of the episode but before therapy was started. The third examination was performed on the day following a nine-day high-dose cortison therapy $(1 \mathrm{~g}$ of prednisolone over five days, $500 \mathrm{mg}$ to the seventh day, and $250 \mathrm{mg}$ to the ninth day) and the final fourth examination was performed four weeks after the onset of the episode. The control group consisted of 18 healthy normal volunteers (nine males and nine females; mean age: 37 years, range: $23-49$ years).

In all serial examinations care was taken to achieve exact repositioning with reference to the bicommissural plane. All examinations were performed on a 0.5 Tesla unit (Gyroscan) with a standard heat coil, using spin-echo sequences (TR $2000 \mathrm{~ms}$, TE $50 / 100 \mathrm{~ms}$ ) with contiguous slices, a slice factor of $1 \cdot 1$, and a slice thickness of $8 \mathrm{~mm}$. Routine scans were displayed on a $256 \times 256$ matrix.

In addition, calculated images were obtained in two different planes, one directed through the bicommissural plane, the second immediately above the corpus callosum parallel to the bicommissural plane through the upper frontal and upper parietal lobe. In the chosen planes IR and SEsequences were obtained as well as a mixed mode sequence with the chosen parameters: SE repetition time $710 \mathrm{~ms}$, IR repetition time $2290 \mathrm{~ms}$, inversion delay $310 \mathrm{~ms}$, echo time $50 \mathrm{~ms}$, slice thickness $8.0 \mathrm{~mm}$, number of measurements two, scan resolution 128 . The techniques by which the calculations were achieved have been described previously. ${ }^{7}$ Methods of minimising error and increasing reproducibility of relaxation time measurements have been considered. ${ }^{8}$ To assure the long-term reproducibility of our measurements, measurements with CuSO 4 standard probes were performed on repeated occasions showing an overall accuracy for $\mathrm{T} 1$ and $\mathrm{T} 2$ within a range of $10 \%$. The calculated images were stored on magnetic tape for off-line measurements.

Measurements were performed with a standard cursor device ( 0.2 square centimetre). The region of interest (ROI) was always chosen on the IR scan, which is thought to be most sensitive for showing plaques. Care was taken to clearly place the ROI outside a plaque region within the normally appearing white matter. The ROI was then kept constant ford $\vec{\omega}$ the measurements. $\mathrm{T} 1$ and $\mathrm{T} 2$ measurements were taken fron $\mathrm{T}$ the upper parietal lobe, the upper frontal lobe, the temporo⿱ parietal region, the temporal lobe, and the frontobasal lobed For each patient or control a total of 20 measurements were taken. Statistical evaluation was performed by means of analysis of variance.

\section{Results}

A total of six patients with seven episodes were evaluated. In one patient the quantitative follow up data could not be evaluated because of technical reasons.

Quantitatively, the base examinations all showed elevated $\mathrm{T} 1$ and $\mathrm{T} 2$ values of the apparently normal

Table 1 Clinical data of six patients (seven episodes) with MS with special reference to the clinical signs featuring an acute relapse and the newly visualised brain lesion as seen on the MR scan within three days after the onset of the relapse

\begin{tabular}{|c|c|c|c|c|}
\hline Case & $\operatorname{Sex}$ & Age/years & Clinical findings during episodes & Cranial MRI-lesion visualised during bout \\
\hline 1 & $\mathbf{M}$ & 65 & $\begin{array}{l}\text { Spinal paraparesis, numbness D5 downwards, } \\
\text { cerebellar tremor }\end{array}$ & $\begin{array}{l}\text { Unchanged lesion left internal capsule, } \\
\text { periventricular lining }\end{array}$ \\
\hline 2 & $\mathbf{M}$ & 29 & Sensorimotor paresis right arm & $\begin{array}{l}\text { Periventricular lesion adjacent to left lateral } \\
\text { ventricle }\end{array}$ \\
\hline 3 & $\mathbf{M}$ & 38 & $\begin{array}{l}\text { Bilateral internuclear ophthalmoplegia, } \\
\text { cerebellar ataxia }\end{array}$ & $\begin{array}{l}\text { Periventricular lesions on lateral and fourth } \\
\text { ventricles increase in size }\end{array}$ \\
\hline 4 & $\mathbf{F}$ & 18 & $\begin{array}{l}\text { Sensory paresis left hand and reduction of } \\
\text { finger tapping }\end{array}$ & $\begin{array}{l}\text { Large lesion in upper frontal and upper parietal } \\
\text { white matter bilaterally }\end{array}$ \\
\hline 5 & $\mathbf{F}$ & 34 & $\begin{array}{l}\text { Bilateral internuclear ophthalmoplegia, increase } \\
\text { of spastic atactic signs on lower } \\
\text { extremities }\end{array}$ & $\begin{array}{l}\text { Paramedian left midbrain lesion. Increase in size of } \\
\text { bilateral lesions in the upper frontal white matter }\end{array}$ \\
\hline $6 \mathrm{a}$ & $\mathbf{F}$ & 30 & Spastic-atactic gait disturbance & $\begin{array}{l}\text { Unchanged bilateral periventricular lesions adjacent } \\
\text { to lateral ventricles }\end{array}$ \\
\hline $6 \mathrm{~b}$ & $\mathbf{F}$ & 30 & $\begin{array}{l}\text { Increase of spastic atactic gait disturbance. } \\
\text { Peripheral facial palsy }\end{array}$ & Unchanged \\
\hline
\end{tabular}


white matter when compared to the control group (table 2). During the series of clinical and therapeutic events (base examination, relapse, treatment phase, follow up) the patient group did not show significant changes for either $\mathrm{T} 1$ or $\mathrm{T} 2$ values. This was true for all brain regions measured (upper frontal, upper parietal, temporoparietal, parietal, or frontobasal).

All patients showed marked clinical improvement after therapy. No consistent changes were found for $\mathrm{T} 1$ values and only individual patients showed $\mathrm{T} 2$ changes compared with their values obtained at the base examination (fig $1 a$ and $b$ ). In two out of six patients there was a significant $\mathrm{T} 2$ elevation during the episode. One of them showed a return to the base value after therapy with a second increase at the follow up examination. One patient showed an elevated T2 throughout the serial study following the base examination which did not change during therapy or the four weeks after. In the other four patients the onset of an episode did not significantly affect the $T 2$ value compared to the base value. In two cases no T2 changes were measured throughout the serial study, in one further patient there was a significant $\mathrm{T} 2$ prolongation after therapy and in another patient the only significant change measured was a $\mathrm{T} 2$ decrease following a second episode at the time of the second follow up examination.

\section{Discussion}

This study shows that $\mathrm{T} 1$ and $\mathrm{T} 2$ measurements of the visually normal cerebral white matter of MS patients

Table 2 Measurements of relaxation times $T 1$ and $T 2$ within the visually normal cerebral white matter of MS patients as compared with normal healthy controls show a significant prolongation in all measured regions (ANOVA ranges:

$*=p<0.05 ; \dagger=p<0.01 ; \S=p<0.001)$.

\begin{tabular}{|c|c|c|c|c|}
\hline \multirow[b]{3}{*}{$\begin{array}{l}\text { Upper parietal } \\
\text { Upper frontal } \\
\text { Temporoparietal } \\
\text { Temporal } \\
\text { Frontobasal }\end{array}$} & \multicolumn{2}{|l|}{ T1-values } & \multicolumn{2}{|l|}{ T2-values } \\
\hline & Normals $(n=18)$ & Patients $(n=13)$ & Normals $(n=18)$ & Patients $(n=13)$ \\
\hline & $\begin{array}{ll}454 & (20) \\
426 & (10) \\
444 & (16) \\
433 & (15) \\
414 & (20)\end{array}$ & $\begin{array}{ll}490 & (14) \dagger \\
484 & (39) \S \\
487 & (21) \\
511 & (38) \S \\
464 & (47) \S\end{array}$ & $\begin{array}{ll}94 \cdot 6 & (5 \cdot 3) \\
88 \cdot 9 & (4 \cdot 2) \\
90 \cdot 0 & (3 \cdot 3) \\
86 \cdot 6 & (4 \cdot 6) \\
82 \cdot 2 & (2 \cdot 6)\end{array}$ & $\begin{aligned} 100.6 & (6 \cdot 1)^{*} \\
93.6 & (7.5) \dagger \\
98.0 & (6.7) \S \\
95.8 & (4.8) \$ \\
86.1 & (6.3) \dagger\end{aligned}$ \\
\hline
\end{tabular}
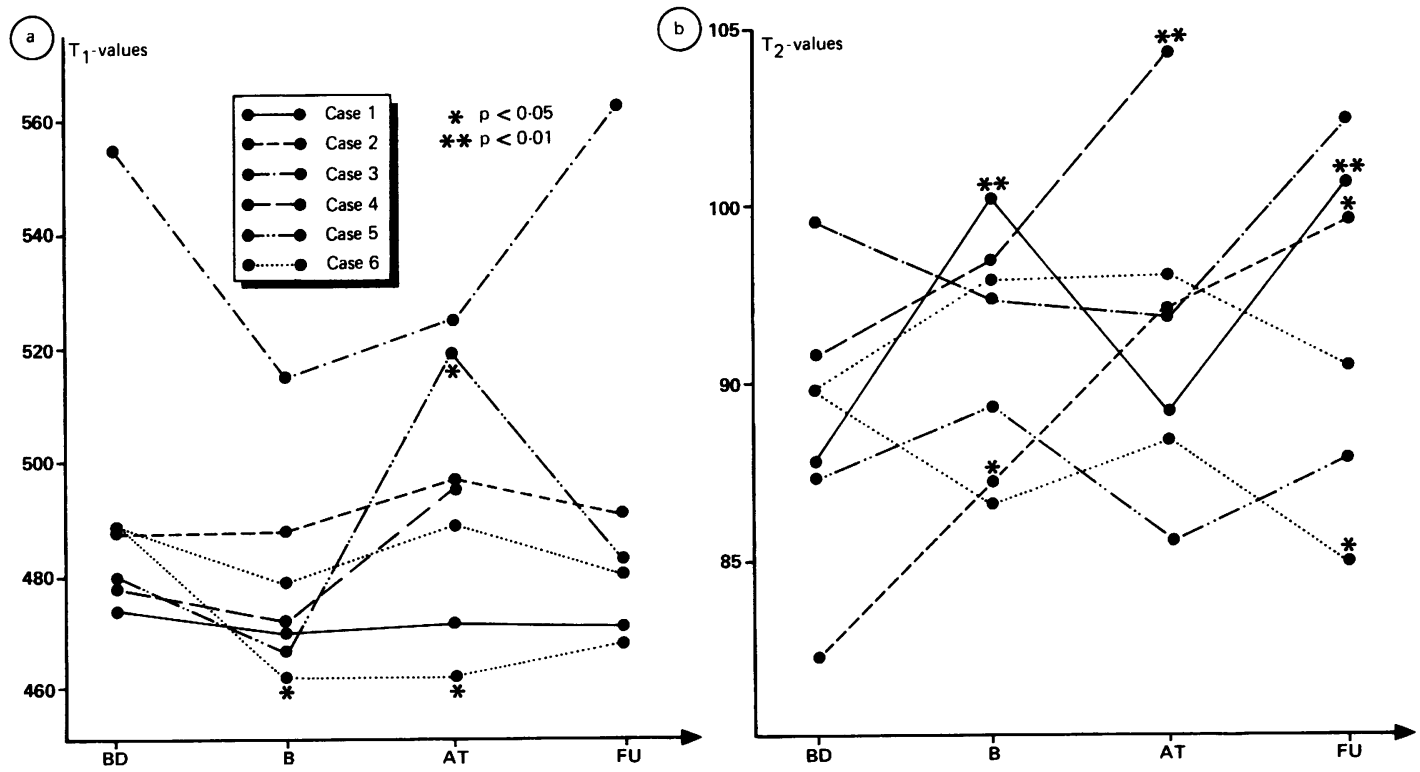

Figs la and 1b Changes of T1-and T2-values within the visually unaffected cerebral white matter of six patients with multiple sclerosis. A total of seven acute relapses were documented. $B D=$ base data (before the onset of an episode), $B=$ within three days after beginning of the bout, before therapy, $A T=$ after treatment (on the day following a nine-day high-dose cortisone therapy), FU = follow up (four weeks after the beginning of the bout). ANOVA ranges see figures. 
do not change in a uniform way during a clinical relapse (fig 2). In addition, such measurements do not predictably change in response to high dose cortisone therapy in our cases. Although it could not be demonstrated in all patients, in individual cases, such
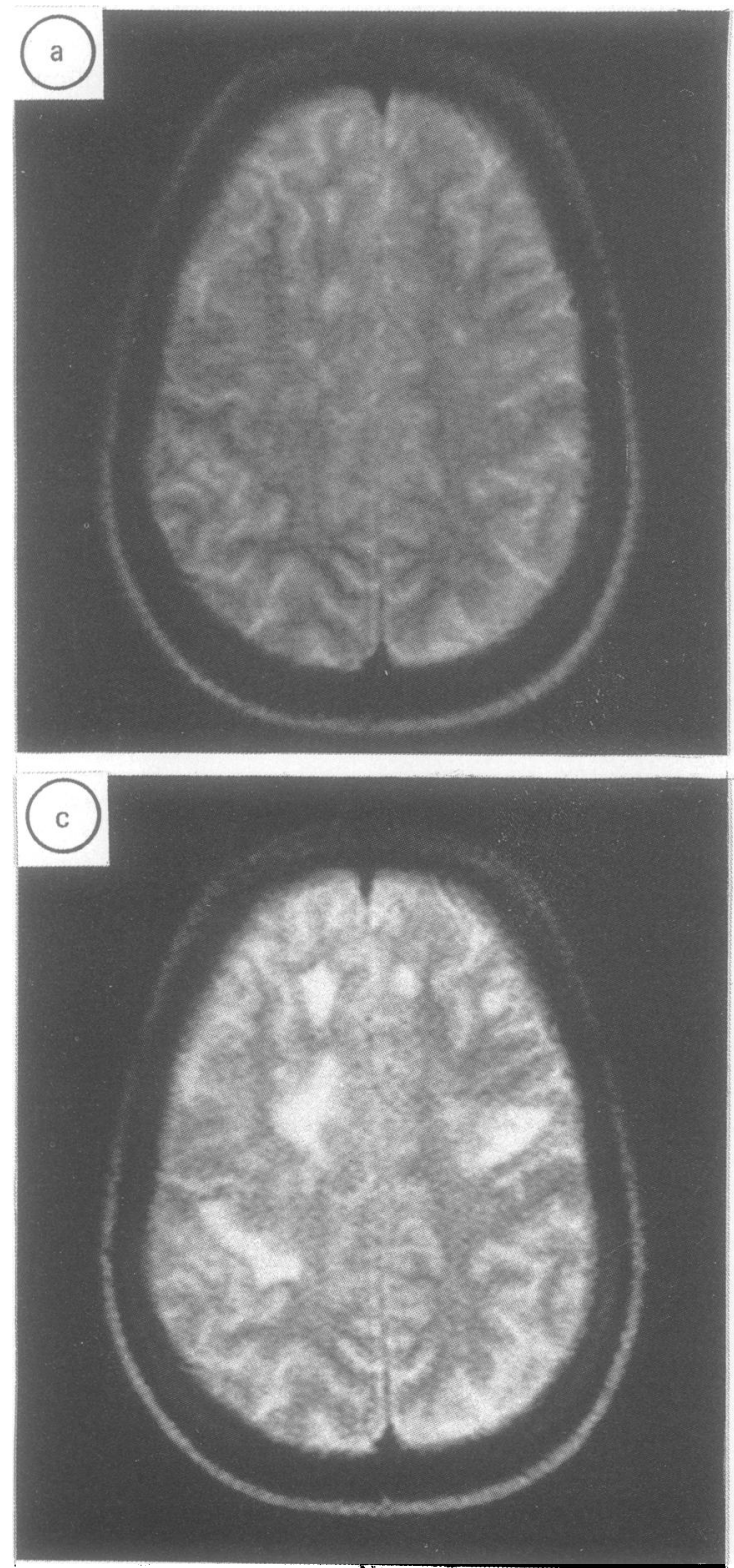

measurements reflect changes of the macromolecular environment. In one patient (case 1) an increase of T2 in the normal white matter could possibly indicate an increase of intercellular water, which was shown to be reversible by cortisone. In the further course a second
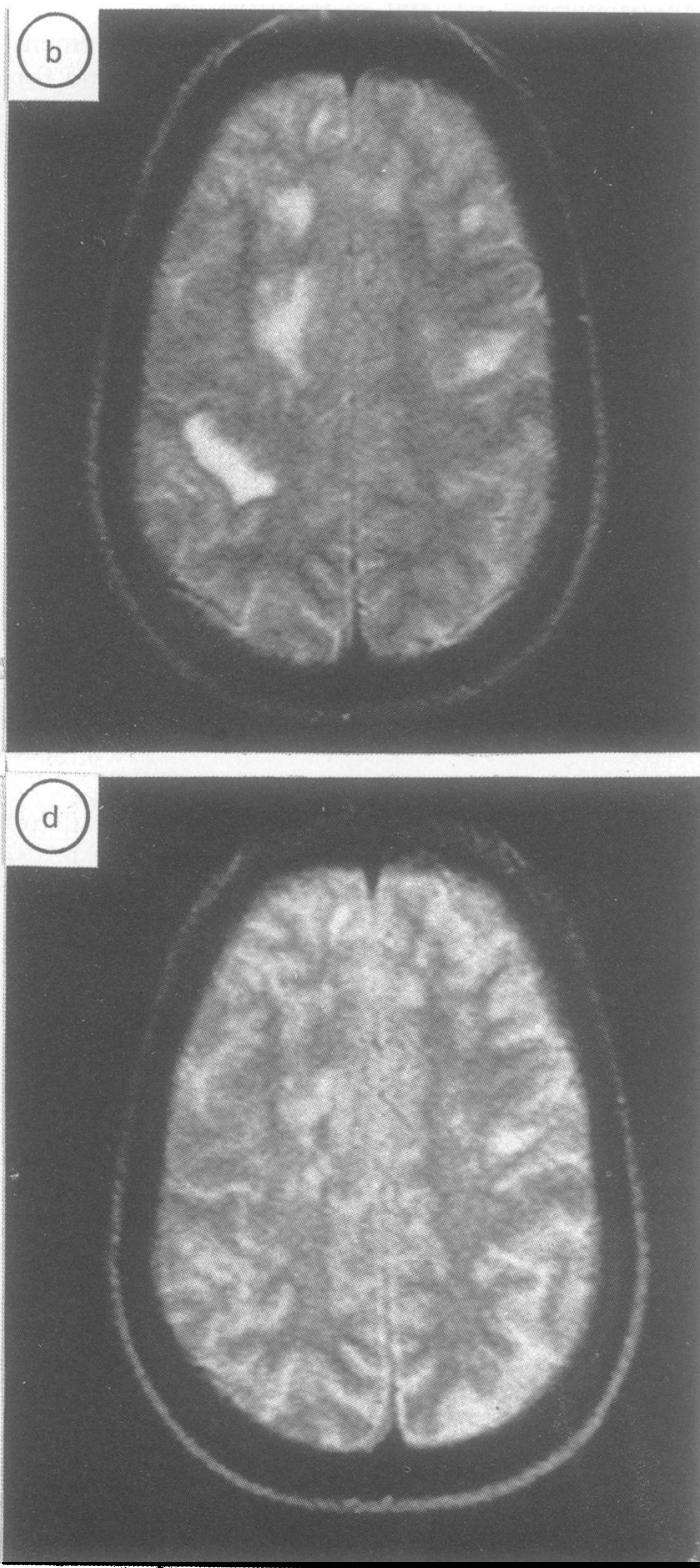

Figs 2a-d Serial MR-examination (SE 100/2000) of corresponding cuts through the upper frontal and parietal lobes of case 2. Further quantitative evaluation of $T 1$ and $T 2$ values within the visually unaffected white matter of the brain did not show a significant change between the scans at the time before or after the acute relapse although all values were elevated in comparison to normal controls. a: base examination. $b$ : on the day following the onset of an acute relapse. $c$ : on the day following a nine-day high-dose cortisone therapy. d: four weeks later. 
increase of $\mathrm{T} 2$ was shown four weeks after therapy which could reflect the beginning of astroglial proliferation within the entire white matter of the brain. But in other patients such measurements were totally unpredictable or did not change at all. Also, the failure to find changes of $\mathrm{T} 1$ during a clinical relapse weighs against the assumption that an increase in the concentration of extracellular water is the sole biochemical factor contributing to the change of $\mathrm{T} 2$. Arguably the degree of elevation of $T 1$ is positively correlated with the total amount of water in a lesion, whereas the degree of $\mathrm{T} 2$ elevation also depends on the total amount of water as well as on the macromolecular environment of the water. ${ }^{910}$ Changes on the macromolecular level within the visually normal white matter has not yet been fully investigated. One quantitative neuropathological study has shown, however, that the main fragments of demyelination (myelin-associated glycoprotein, basic myeloprotein, and proteolipoprotein) cannot be traced within the normally appearing white matter of MS brains, whereas within the plaque- and periplaque area they can be found in abnormally high amounts." It therefore cannot be assumed that fragments of demyelination contribute to the $\mathrm{T} 2$ values within the normal white matter.

In one other study ${ }^{6}$ multiple sclerosis patients have been investigated using quantitative MRI immediately before as well as three to seven days after a five day treatment with intravenous methylprednisolone. Similarly in our study no significant change of T2 values was found within the apparently normal cerebral white matter in the pre- and post treatment measurements, but a significant decrease of $\mathrm{T} 1$ was noted within the "normal" white matter which the authors ascribed to the antioedematous effect of cortisone. Although the patients in that study are comparable to our group of patients (in terms of age, disability status and applied cortisone dose), we failed to find such a significant change of $\mathrm{T} 1$ values in our group. We are inclined to explain this difference through the activity status of the disease. We included only patients with an acute relapse and only these patients received cortisone therapy in our series, whereas Kesselring et $\mathrm{al}^{6}$ applied cortisone only to clinically stable patients. We therefore conclude that, in acute relapses of multiple sclerosis, additional macromolecular changes play a role in the intercellular compartment of the apparently unaffected white matter of the brain thus influencing the $T 1$ values. Such changes may seem to be effective in the relapsing phase and not in clinically stable patients, where the effect of high-dose cortisone is mainly reflected in a decrease of T1 within the "normal" white matter. This might explain why our T1 measurements did not significantly change in response to high-dose cortisone therapy in spite of a clear-cut remission achieved in all our patients.

Measurements of $\mathrm{T} 1$ and $\mathrm{T} 2$ within the plaque areas have not been evaluated in this study. Other reports show that neither age nor activity of the plaque can be reliably assessed, although a prolongation of $\mathrm{T} 1$ and $\mathrm{T} 2$ is frequently seen within an active plaque. ${ }^{312}$ However, the ranges of the values obtained show considerable overlap, so that no conclusions can be drawn from single measurements within plaque areas. $^{12}$ Therefore, serial measurements of plaque areas with and without application of Ga-DTPA can be considered the most reliable biological marker reflecting the activity of the disease..$^{13-15}$

\section{References}

1 Ormerod IEC, Johnson G, MacManus D, du Boulay EPGH, McDonald WI. Relaxation times of apparently normal cerebral white matter in multiple sclerosis. Acta Radiol Suppl 1986;386:382-4.

2 Lacomis D, Osbakken M, Gross G. Spin-lattice relaxation (T1) times of cerebral white matter in multiple sclerosis. Magn Res Med 1986;3:194-202.

3 Ormerod IEC, Miller DH, McDonald WI, et al. The role of NMR-imaging of multiple sclerosis and isolated lesions: a quantitative study. Brain 1987;110:1579-616.

4 Allen IV. Hydrolytic enzymes in multiple sclerosis. In: Zimmerman HR, ed. Progress in Neuropathology. New York: Raven Press, 1983:1-17.

5 Brainin M, Reisner T, Neuhold A, Lang S, Deecke L. Mitbeteiligung der scheinbar normalen weissen Hirnsubstanz am Krankheitsprozess der multiplen Sklerose. Nervenarzt 1989;60:159-62.

6 Kesselring J, Miller D, McManus DG, et al. Quantitative magnetic resonance imaging in multiple sclerosis: the effect of highdose intravenous methylprednisolone. $J$ Neurol Neurosurg Psychiatry 1989;52:14-7.

7 In den Kleef JJE, Cuppen JJM. RLSQ: T1, T2 and p calculations, combing ratios and least squares. Magn Res Med 1987;5:513-24.

8 Hickey DS, Checkley D, Aspden RM, Naughton A, Jenkins JPR, Isherwood I. A method for the clinical measurement of relaxation times in magnetic resonance imaging. Br J Radiol 1986;59:565-76.

9 Mathur-de Vre R. Biomedical implications of the relaxation behaviour of water related to NMR imaging. $\mathrm{Br} J$ Radiol 1984;57:955-76.

10 Miller DH, Rudge P, Johnson G, et al. Serial gadolinium enhanced magnetic resonance imaging in multiple sclerosis. Brain 1988;111:927-39.

11 Moller JR, Yanagisawa K, Brady RO, et al. Myelinassociated glycoprotein in multiple sclerosis: a quantitative and qualitative analysis. Ann Neurol 1987;22:469-74.

12 Larsson HBW, Frederiksen JL, Kjaer L, Henriksen O, Oleson $\mathrm{J}$. In vivo determination of $\mathrm{T} 1$ and $\mathrm{T} 2$ in the brain of patients with severe but stable multiple sclerosis. Magn Res Med 1988;7:43-55.

13 Grossman RI, Gonzalez-Scarano F, Atlas SW, Galetta S, Silverberg DH. Multiple sclerosis: gadolinium enhancement in MR imaging. Radiology 1986;161: 721-5.

14 Paty DW, Oger JJ, Kastrukoff LF, et al. Biologic versus clinical MS. Neurology 1989;39:151-3.

15 Isaac C, Li DKB, Genton M, et al. Multiple sclerosis: a serial study using MRI in relapsing patients. Neurology 1988:38:1511-5. 